\title{
Analysis of Pad Reinforced Openings in Pressure Vessels
}

\author{
Muhammad Raza Cheema \\ Design Engineer \\ Zamil Process Equipment Company, Dammam \\ Saudi Arabia
}

\author{
Niyamatullah Ataullah Patel \\ Design Engineer \\ Zamil Process Equipment Company, Dammam \\ Saudi Arabia
}

\author{
Aftab Alam \\ Design Engineer \\ Zamil Process Equipment Company, Dammam \\ Saudi Arabia
}

\begin{abstract}
Openings, also called Nozzles, in Pressure Vessels are provided to attach piping and other instruments. Piping attached, exerts external forces on openings which create local stresses on the Nozzle-to-Shell junction. Determination of failure stresses is necessary for both safety and economics. Currently WRC 107 (also WRC 537) is the most popular and acceptable bulletin for calculation of local stresses. The bulletin is based on P.P. Bijilaard's experimental work and aimed at providing methods for determining the stresses in pressure vessel-nozzle connections subjected to various forms of external loadings. This bulletin has advantage over other methods for its safety and provides results in very short span of time but geometrical limitations of this bulletin leads to non-conservative results, especially for large openings. Finite Element Method can be used to overcome the geometric limitation problem. For this purpose, this paper is produced to provide finite element procedure for pad reinforced nozzles and also a comparison is made with WRC method.
\end{abstract}

Key Words: Pressure Vessel; Nozzle; Finite Element Analysis; FEA

\section{INTRODUCTION}

Pressure vessels, piping tees, boilers and reactors are typical examples of applications where safe and economical design criteria must be used in view of structural design. Nozzle connections subjected to internal pressure and external loads are the most common configurations in many engineering applications. One of the problems concerning design of the nozzle connections is the application of the proper reinforcements for stress reduction. To ensure the safety of nozzle connections different types of connections are used. These connections include welded pad reinforcement, self-reinforced nozzles, and internally protruded connections and toros transitions.

Due to importance of pressure vessels in engineering applications and the safety hazards in case of any accidents, a versatile research has been performed on assessing the safety of pressure vessels under different loading conditions. There are many codes which provide the rules and regulations to ensure the safe design of equipment. Significant researches have been done for evaluating the stresses around nozzle junctions. The accurate assessment of stresses at cylindrical junctions can ensure the safe and economical design.

Typical pressure vessel design codes, such as ASME Section VIII, cannot address all design cases. For instance, external loads on nozzles are not addressed within the Code. In such cases, Engineers need to go outside of the Code and apply recognized design procedures such as finite element analysis. Simplified calculation methods commonly used in the PVP industry such as WRC 107/297 are based on limited test data and have geometric limitations. When these geometric limitations are not followed the results become inaccurate. Finite element analysis has no limitations and provides realistic answers for all cases.

\section{LITERATURE REVIEW}

M. D. Xue in his study calculated stress at intersection of cylindrical shells analytically and presented formulas for calculation of stresses. But the paper didn't mention any comparison with conventional procedures of stress calculations like WRC 107 and WRC 297. [1] C. J. Dekker performed finite element analysis for calculation of stress on nozzle intersections and also presented comparison with WRC results. But only one type of load was applied on the nozzle at a time. This practice is correct for studying the effect of individual loads but is not correct from practical point of view as combined loads are applied in practical applications. [2] Z. F. Sang performed both finite element method and experimental work to calculate the stresses on nozzle intersections. But study was limited to only Internal Pressure. Also no comparison was presented with WRC method which is the most traditional method used to calculate the stresses at nozzle intersections. [3] Z. F. Sang in another study calculated the effect of out-of-plane bending moment on nozzle intersections. But again he only considered circumferential moment for the study. [4] You-Hong in his work calculated the stresses on cylindrical intersections of ratio upto 0.8 . He performed 3D non-linear finite element analysis for calculating the results. But in his work only internal pressure was considered for loading and no comparison was made with WRC method. [5] Aleksandar Petrovic in his work performed finite element analysis to calculate the effect of external loads on cylindrical intersections but he ignored the effect of internal pressure for his results. [6] A. Th. Diamantoudis in his work did a comparison of design by analysis and design by formula. For his study he also considered integrally reinforced nozzle for the analysis. But study was limited to internal pressure only. [7] V. N. Skopinsky did a great effort 
in comparative study of different types of nozzle reinforcements. He performed finite element method to calculate the effect different kind of reinforcements on stresses on intersection. But only one kind of load was considered at a time also no comparison was made with WRC method. [8] C. J. Dekker in another study performed a comparison of different design by formula methods. He also presented results obtained by finite element method for comparison but he only considered internal pressure for his study. [9]

In this study stresses at intersection of cylindrical shells will be calculated by using finite element method. Effect of combined loads Pressure, Axial Load, Circumferential Moment and Longitudinal Moment will be considered for this study. Magnitude and Location of maximum and minimum stresses will be evaluated. Also stress envelop will be measured in this study. The results will be discussed and comparison will be made with ASME code rules for reinforcement of nozzles and WRC 107 and WRC 297 calculations.

\section{STRESS CATEGORIES}

Before discussing the analytical methods, it is beneficiary to first describe the types of stresses to be calculated around nozzle junctions. According to ASME Section VIII Division 2 Part 5, stresses can be divided into three categories: primary, secondary, and peak stresses. Primary stresses can then be divided into general membrane stresses, local membrane stresses, and primary bending stresses. In summary, there are the following types of stresses.

\section{A. General Membrane Stresses $\left(\sigma_{m}\right)$}

They correspond to the average value of the stresses through the thickness of the vessel. The fundamental characteristic of these stresses is that a potential yielding of the material does not cause a redistribution of the stresses, since the same stress is present in all the surrounding fibers. A typical example of general membrane stresses is represented by the average values of the stresses acting in a cylinder without holes.

\section{B. Local Membrane Stresses $\left(\sigma_{l}\right)$}

These are also the average values of the stresses through the thickness in the analyzed section. In contrast with the general membrane stresses, they involve a limited area of the component, and this means that the surrounding fibers are subject to membrane stress of lower value. A potential yielding of the material happens together with a redistribution of the stresses to the surrounding fibers that are still able to contribute to the local resistance of material, since they are not yielded. Typical examples of stresses of this kind are the membrane stresses produced in the cylinder and in the dished heads in correspondence with their junction, or the membrane stresses that occur in the cylinder (or in the sphere), and in the nozzle welded on the same in correspondence of a hole.

\section{Primary Bending Stresses $\left(\sigma_{b}\right)$}

These stresses belong to the category of primary stresses, such as the ones mentioned above, but they are characterized by the fact that their value is proportional to the distance of the fiber from the neutral axis of the section. As the previous ones, they derive from the balance conditions between internal stresses and external forces acting upon the vessel (pressure or mechanical loads). A typical example is represented by the stresses at the center of a flat head. The stresses produced by bending moments exerted on a vessel fall into this category as well.

\section{Secondary Stresses $(Q)$}

These are the self-limiting stresses. Their only purpose is to create the balance of the deformations and, therefore, once the required deformations are produced (even though this happens through the yielding of the material) they do neither cause further deformations nor do they force the intervention of the surrounding fibers, as is the case for the local membrane stresses. The stresses in correspondence of the junction between cylinder and heads belong to this category (not the membrane ones because in that case they are local membrane stresses); the stresses still not related to membranes in the cylinder or in the sphere and in the welded nozzles in correspondence of a hole belong to this category, as well. In this last case local peaks due to the presence of sharp edges are excluded, as they belong to the next category. The stresses due to thermal flux are secondary, as well.

\section{E. Peak Stresses $(F)$}

Generally speaking, a peak stress is any type of stress that will show a maximum in the section under test. From this point of view peak stresses are the local membrane stresses (as they are locally greater than the general membrane stresses) and the secondary stresses. This category consists only of those stresses, present in a limited area of the component and in a limited area of the section under test, that do not produce significant deformations, and that represent a potential possibility of rupture due to fragility or fatigue. Therefore Peak stresses are induced by special geometrical characteristics of the coupled elements that can often be eliminated or at least reduced through an appropriate management of the couplings. Moreover, the stresses due to a rapid variation in the temperature of the fluid inside the vessel belong to this category, as well.

\section{ANALYTICAL METHODS}

Due to the scope of this paper only brief description of three commonly used methods will be discussed here. The detail of the procedure can be found in respective documentations of the methods. The stresses are being calculated and presented for comparison with finite element method.

\section{A. ASME Section VIII Division 2}

This is the mostly commonly used code for design of pressure vessels and nozzle connections. This code uses the pressure area method for designing the nozzle connections. The limitation with this method is that it provides stressed due to internal pressure only. For external pressure the code directs the designer to use other analytical methods, WRC 107, WRC 297 and FEA, for calculating the stresses.

\section{B. WRC 107}

This is the most widely used analytical method for calculating the stresses around attachments on shells. The shape of the attachment can be rectangular, square and round. This method provides stresses for both cylindrical and spherical shells. The limitation in this method is that it 
considers a rigid attachment in the shells due to which stresses cannot be calculated on nozzles. Further this method provides conservative results for nozzle to shell junction ration around 0.3 for larger nozzles the stresses can be non-conservative.

\section{WRC 297}

This method provides stresses for both shell and nozzle. But the following limitations limit the use of this method.

- This bulletin is only applicable to the intersection of nozzle whose axis is perpendicular to vessel wall.

- $\quad$ Both nozzle and vessel should be treated as thin walled cylindrical shells. According this theory for thin shell theory is valid for $\mathrm{d} / \mathrm{t} \geq 20, \mathrm{D} / \mathrm{T} \geq 20$ and $\mathrm{d} / \mathrm{T} \geq 5$.

- $\mathrm{D} / \mathrm{T} \leq 2500$ is recommended because this theory is not applicable to nonlinear solutions.

- $\mathrm{d} / \mathrm{t} \leq 100$.

- The theory is applicable to isolated nozzles only. This means that nozzle should be sufficiently remote from any discontinuity so that the effect of other discontinuity is negligible. For this bulletin, if the distance between discontinuities is $2 \sqrt{D T}$ on vessel wall or $2 \sqrt{ } d t$ on nozzle wall then the results will be reasonable.

- This theory is not applicable to nozzles that protrude the vessel

\section{FINITE ELEMENT ANALYSIS}

Linear Elastic analysis was performed in the study to evaluate the stresses around the junction of cylindrical shells. Maximum Shear stress (Tresca) Criteria was used to evaluate the combined stresses. One assumption that was made here was, stress calculation in weld area was omitted. This approach (not using stresses within the volume of the intersection) has been supported by past Pressure Vessel Research Council (PVRC) publications and is also supported by the new ASME Section VIII, Division 2, Annex 5.A. The concept is that the stresses within the intersection volume do not represent valid membrane or bending stresses. However, the stresses in the shells directly adjacent to this zone are valid. Also it is found that high stresses usually occur at the toe of filled weld not inside the weld. The stresses in the weld are important for fatigue evaluation only.

FE Pipe version 6.5 was used to study the stress patterns around the junction. FE/Pipe is a finite element analysis specifically designed for use in the pressure vessel and piping (PVP) industry. What separates FE/Pipe from the rest of the general FEA tools is its ability to rapidly construct PVP geometries. FE/Pipe makes modeling typical pressure vessel and piping geometries faster and easier than is possible with general FEA tools due to the parametric design philosophy. The parametric approach used in FE/Pipe permits finite element analysts to construct accurate model.

\section{A. Dimensions}

For the present study problem identified for the analysis is taken form a real project of an organization dealing with design of pressure vessels. The geometry of the problem is as follows.
Table 1 Dimensions

\begin{tabular}{|l|l|}
\hline Cylinder Length (L) & $6800 \mathrm{~mm}$ \\
\hline Cylinder Diameter (D) & $3100 \mathrm{~mm}$ \\
\hline Nozzle Diameter (d) & $762 \mathrm{~mm}$ \\
\hline Reinforcement Pad Diameter $\left(\mathrm{d}_{\mathrm{P}}\right)$ & $1350 \mathrm{~mm}$ \\
\hline Cylinder Thickness $(\mathrm{T})$ & $14 \mathrm{~mm}$ \\
\hline Nozzle Thickness $(\mathrm{t})$ & $14 \mathrm{~mm}$ \\
\hline Pad Thickness $\left(\mathrm{t}_{\mathrm{P}}\right)$ & $14 \mathrm{~mm}$ \\
\hline
\end{tabular}

\section{B. Material Properties}

The material used for the study was SA-516 Gr 70 for shell and SA-106 Gr B was used for nozzle geometry. The following properties are given at $250^{\circ} \mathrm{C}$.

Table 2 Shell Material

\begin{tabular}{|l|l|}
\hline \multicolumn{2}{|l|}{ Shell Material } \\
\hline Material & SA-516-70 \\
\hline Allowable Stress & $143.5 \mathrm{MPa}$ \\
\hline Modulus of Elasticity & $189 \mathrm{GPa}$ \\
\hline Yield Stress & $215.6 \mathrm{MPa}$ \\
\hline Tensile Stress & $482.7 \mathrm{MPa}$ \\
\hline
\end{tabular}

Table 3 Nozzle Material

\begin{tabular}{|l|l|}
\hline \multicolumn{2}{|l|}{ Nozzle Material } \\
\hline Material & SA-106-B \\
\hline Allowable Stress & $132.2 \mathrm{MPa}$ \\
\hline Modulus of Elasticity & $189 \mathrm{GPa}$ \\
\hline Yield Stress & $198.2 \mathrm{MPa}$ \\
\hline Tensile Stress & $413.7 \mathrm{MPa}$ \\
\hline
\end{tabular}

\section{Element Type}

The element type used for this study was 8 node isoparametric shell element. The element has been found to be remarkably insensitive to shape and less sensitive to size than many of the more "formally" derived element types. Stiffness convergence is good even with the crudest mesh and nonaveraged stress calculations give a good visual indication of the adequacy of the stress state. The formulation can be found in many finite element texts.

\section{Geometry Modeling}

Vessel was modeled for both accuracy and to save time. Ends of vessel were taken sufficiently away from nozzle so that there is no influence of end boundary conditions on stresses. Finer mesh was employed close to the nozzle and for economic purposes coarser mesh was employed on region far from nozzle.

\section{E. Meshing}

For this study, finer mesh was used at the junction of nozzle. As recommended by previous work, minimum 96 elements were used in nozzle area near junction. Element aspect ratio was kept under 3:1. And element edge angle was kept between 60 to $120 \mathrm{deg}$. Convergence study was performed to optimize the mesh size.

\section{F. Boundary Conditions}

As the problem for study is a horizontal drum. And for industrial designs, vessel is mostly supported on saddle supports whose one end is kept fixed and other end is allowed to slide in horizontal direction to minimize the stresses due to temperature. So in this study one end of vessel was kept fixed and other end was allowed to move in longitudinal direction 
of cylinder. Also vessel was allowed to deform in radial direction at both ends.

Loads were applied at free end of nozzle. The following loads were applied on nozzle.
Table 4 Loadings

\begin{tabular}{|l|l|}
\hline Pressure & $0.35 \mathrm{MPa}$ \\
\hline Axial Force & $45000 \mathrm{~N}$ \\
\hline In-plane Moment & $65000 \mathrm{~N}-\mathrm{m}$ \\
\hline Out-plane Moment & $65000 \mathrm{~N}-\mathrm{m}$ \\
\hline
\end{tabular}

\section{TABLES AND FIGURES}

A. Tables

Table 5 Axial Load Case (MPa)

\begin{tabular}{|c|c|c|c|c|c|c|c|c|c|c|}
\hline \multirow{2}{*}{ Load P } & \multicolumn{2}{|c|}{ FEA with Pressure } & \multicolumn{2}{|c|}{ FEA w/o Pressure } & \multirow{2}{*}{$\begin{array}{c}\begin{array}{c}\text { WRC 107 } \\
\text { with } \\
\text { Pressure }\end{array} \\
\begin{array}{c}\text { Shell at } \\
\text { Junction }\end{array}\end{array}$} & \multirow{2}{*}{$\begin{array}{c}\text { WRC } 107 \\
\text { w/o Pressure } \\
\text { Shell at } \\
\text { Junction }\end{array}$} & \multicolumn{2}{|c|}{$\begin{array}{c}\text { WRC } 297 \text { with } \\
\text { Pressure }\end{array}$} & \multicolumn{2}{|c|}{$\begin{array}{l}\text { WRC } 297 \text { w/o } \\
\text { Pressure }\end{array}$} \\
\hline & $\begin{array}{c}\text { At } \\
\text { Nozzle }\end{array}$ & At Shell & $\begin{array}{c}\text { At } \\
\text { Nozzle }\end{array}$ & At Shell & & & $\begin{array}{c}\text { At } \\
\text { Nozzle }\end{array}$ & $\begin{array}{c}\text { At } \\
\text { Shell }\end{array}$ & At Nozzle & $\begin{array}{c}\text { At } \\
\text { Shell }\end{array}$ \\
\hline 4500 & 139 & 88 & 12 & 4 & 70 & 3 & 147 & 95 & 5 & 2 \\
\hline 9000 & 137 & 88 & 18.5 & 6 & 70 & 5 & 153 & 97 & 10 & 3 \\
\hline 13500 & 136 & 88 & 25 & 8 & 70 & 8 & 158 & 99 & 16 & 4.5 \\
\hline 18000 & 135 & 87 & 31.5 & 10 & 71 & 10 & 163 & 101 & 21 & 6 \\
\hline 22500 & 134 & 87 & 38 & 12 & 71 & 13 & 169 & 102 & 26 & 8 \\
\hline 27000 & 132 & 86 & 44.5 & 14 & 71 & 16 & 174 & 104 & 32 & 10 \\
\hline 31500 & 131 & 86 & 51 & 16 & 71 & 18 & 180 & 106 & 38 & 12 \\
\hline 36000 & 130 & 86 & 57.5 & 18 & 71 & 21 & 185 & 108 & 42 & 14 \\
\hline 40500 & 128 & 85 & 64 & 20 & 71 & 23 & 190 & 109 & 48 & 16 \\
\hline 45000 & 130 & 87 & 70 & 22 & 71 & 26 & 196 & 111 & 54 & 18 \\
\hline
\end{tabular}

Table 6 Circumferential Load Case (MPa)

\begin{tabular}{|c|c|c|c|c|c|c|c|c|c|c|}
\hline \multirow{2}{*}{ Load Mc } & \multicolumn{2}{|c|}{ FEA with Pressure } & \multicolumn{2}{|c|}{ FEA w/o Pressure } & \multirow{2}{*}{$\begin{array}{c}\text { WRC } 107 \\
\text { with } \\
\text { Pressure } \\
\text { Shell at } \\
\text { Junction }\end{array}$} & \multirow{2}{*}{$\begin{array}{c}\text { WRC } 107 \\
\text { w/o Pressure } \\
\text { Shell at } \\
\text { Junction }\end{array}$} & \multicolumn{2}{|c|}{$\begin{array}{l}\text { WRC } 297 \text { with } \\
\text { Pressure }\end{array}$} & \multicolumn{2}{|c|}{$\begin{array}{l}\text { WRC } 297 \text { w/o } \\
\text { Pressure }\end{array}$} \\
\hline & $\begin{array}{c}\text { At } \\
\text { Nozzle }\end{array}$ & At Shell & $\begin{array}{c}\text { At } \\
\text { Nozzle }\end{array}$ & At Shell & & & $\begin{array}{c}\text { At } \\
\text { Nozzle }\end{array}$ & $\begin{array}{c}\text { At } \\
\text { Shell }\end{array}$ & At Nozzle & $\begin{array}{c}\text { At } \\
\text { Shell }\end{array}$ \\
\hline 6500 & 121 & 95 & 46 & 18 & 50 & 11 & 166 & 102 & 24 & 8 \\
\hline 13000 & 152 & 107 & 85.5 & 33 & 61 & 22 & 189 & 110 & 48 & 16 \\
\hline 19500 & 194 & 119 & 125 & 48 & 72 & 33 & 213 & 118 & 71 & 24 \\
\hline 26000 & 236 & 131 & 165 & 63 & 83 & 44 & 237 & 126 & 95 & 32 \\
\hline 32500 & 278 & 143 & 205 & 78 & 94 & 55 & 261 & 134 & 118 & 40 \\
\hline 39000 & 320 & 155 & 245 & 93.5 & 105 & 66 & 284 & 142 & 142 & 48 \\
\hline 45500 & 363 & 167 & 285 & 109 & 116 & 77 & 308 & 150 & 166 & 56 \\
\hline 52000 & 405 & 180 & 325 & 124 & 127 & 88 & 332 & 158 & 190 & 65 \\
\hline 58500 & 447 & 192 & 365 & 139 & 138 & 100 & 356 & 166 & 214 & 73 \\
\hline 65000 & 489 & 205 & 404 & 154 & 150 & 111 & 380 & 175 & 238 & 82 \\
\hline
\end{tabular}

Table 7 Longitudinal Load Case (MPa)

\begin{tabular}{|c|c|c|c|c|c|c|c|c|c|c|}
\hline \multirow{2}{*}{ Load Ml } & \multicolumn{2}{|c|}{ FEA with Pressure } & \multicolumn{2}{|c|}{ FEA w/o Pressure } & \multirow{2}{*}{$\begin{array}{l}\text { WRC } 107 \\
\text { with } \\
\text { Pressure } \\
\text { Shell at } \\
\text { Junction }\end{array}$} & \multirow{2}{*}{$\begin{array}{c}\text { WRC } 107 \\
\text { w/o Pressure } \\
\text { Shell at } \\
\text { Junction }\end{array}$} & \multicolumn{2}{|c|}{$\begin{array}{l}\text { WRC } 297 \text { with } \\
\text { Pressure }\end{array}$} & \multicolumn{2}{|c|}{$\begin{array}{l}\text { WRC } 297 \text { w/o } \\
\text { Pressure }\end{array}$} \\
\hline & $\begin{array}{c}\text { At } \\
\text { Nozzle }\end{array}$ & At Shell & $\begin{array}{c}\text { At } \\
\text { Nozzle }\end{array}$ & At Shell & & & $\begin{array}{c}\text { Att } \\
\text { Nozzle }\end{array}$ & $\begin{array}{c}\text { At } \\
\text { Shell }\end{array}$ & At Nozzle & $\begin{array}{c}\text { At } \\
\text { Shell }\end{array}$ \\
\hline 6500 & 131 & 90 & 18 & 8 & 75 & 5 & 153 & 86 & 11 & 3 \\
\hline 13000 & 145 & 95 & 32.5 & 14 & 80 & 11 & 164 & 90 & 22 & 6 \\
\hline 19500 & 158 & 101 & 47 & 20 & 85 & 16 & 176 & 94 & 34 & 10 \\
\hline 26000 & 171 & 106 & 61.5 & 26.5 & 91 & 22 & 187 & 98 & 45 & 13 \\
\hline 32500 & 185 & 111 & 76 & 33 & 96 & 27 & 198 & 102 & 56 & 17 \\
\hline 39000 & 199 & 117 & 91 & 39.5 & 101 & 33 & 210 & 105 & 68 & 20 \\
\hline 45500 & 212 & 122 & 106 & 46 & 106 & 38 & 221 & 109 & 78 & 23 \\
\hline 52000 & 226 & 127 & 120.5 & 52.5 & 111 & 43 & 232 & 113 & 90 & 26 \\
\hline 58500 & 240 & 133 & 135 & 59 & 116 & 49 & 244 & 117 & 101 & 30 \\
\hline 65000 & 254 & 138 & 150 & 65 & 121 & 54 & 255 & 121 & 112 & 33 \\
\hline
\end{tabular}


Table 8 Combined Load Case (MPa)

\begin{tabular}{|c|c|c|c|c|c|c|c|c|c|c|}
\hline \multirow[t]{2}{*}{ Load L } & \multicolumn{2}{|c|}{ FEA with Pressure } & \multicolumn{2}{|c|}{ FEA w/o Pressure } & \multirow{2}{*}{$\begin{array}{c}\text { WRC 107 } \\
\text { with } \\
\text { Pressure } \\
\text { Shell at } \\
\text { Junction }\end{array}$} & \multirow{2}{*}{$\begin{array}{c}\begin{array}{c}\text { WRC } 107 \\
\text { w/o Pressure }\end{array} \\
\begin{array}{c}\text { Shell at } \\
\text { Junction }\end{array}\end{array}$} & \multicolumn{2}{|c|}{$\begin{array}{l}\text { WRC } 297 \text { with } \\
\text { Pressure }\end{array}$} & \multicolumn{2}{|c|}{$\begin{array}{c}\text { WRC } 297 \text { w/o } \\
\text { Pressure }\end{array}$} \\
\hline & $\begin{array}{c}\text { At } \\
\text { Nozzle }\end{array}$ & At Shell & $\begin{array}{c}\text { At } \\
\text { Nozzle }\end{array}$ & At Shell & & & $\begin{array}{c}\text { At } \\
\text { Nozzle }\end{array}$ & $\begin{array}{c}\text { At } \\
\text { Shell }\end{array}$ & At Nozzle & $\begin{array}{c}\text { At } \\
\text { Shell }\end{array}$ \\
\hline $10 \%$ & 154 & 93 & 42 & 18 & 50 & 14 & 171 & 103 & 28 & 10 \\
\hline $20 \%$ & 169 & 97 & 89 & 37 & 61 & 27 & 200 & 113 & 58 & 19 \\
\hline $30 \%$ & 188 & 103 & 136 & 56 & 72 & 41 & 229 & 123 & 87 & 28 \\
\hline $40 \%$ & 214 & 114 & 183.5 & 74.5 & 82 & 55 & 258 & 133 & 116 & 39 \\
\hline $50 \%$ & 249 & 128 & 231 & 93 & 93 & 68 & 288 & 143 & 145 & 49 \\
\hline $60 \%$ & 291 & 142 & 278 & 112 & 104 & 82 & 317 & 153 & 174 & 58 \\
\hline $70 \%$ & 333 & 156 & 325 & 131 & 115 & 96 & 346 & 162 & 204 & 69 \\
\hline $80 \%$ & 376 & 170 & 372 & 150 & 126 & 109 & 375 & 172 & 233 & 79 \\
\hline $90 \%$ & 424 & 183 & 419 & 169 & 137 & 123 & 404 & 182 & 262 & 88 \\
\hline $100 \%$ & 472 & 197 & 466 & 188 & 148 & 137 & 433 & 192 & 292 & 99 \\
\hline
\end{tabular}

B. Figures

\section{Stress Comparions due to Axial Load}

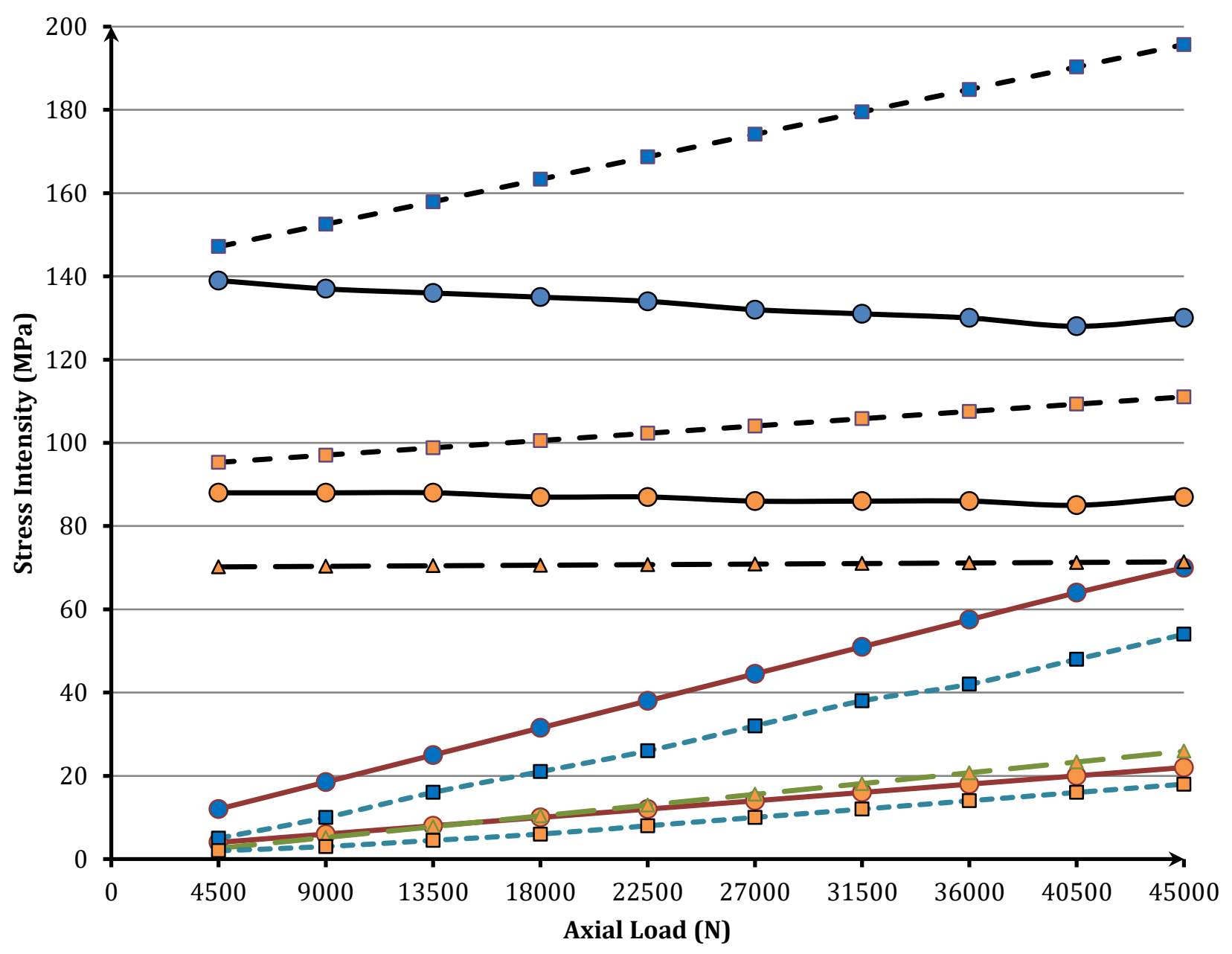

\footnotetext{
- FEA with Pressure At Nozzle

- FEA with Pressure At Shell

FEA without Pressure At Nozzle

- FEA without Pressure At Shell

$\triangle-$ WRC 107 with Pressure At Shell

$\triangle-$ WRC 107 without Pressure At Shell

-

- $\square$ - WRC 297 with Pressure At Shell

$-\square-\bullet$ WRC 297 Without Pressure At Nozzle - $\square-\bullet$ WRC 297 Without Pressure At Shell
}

Figure 1 Axial Load Case 


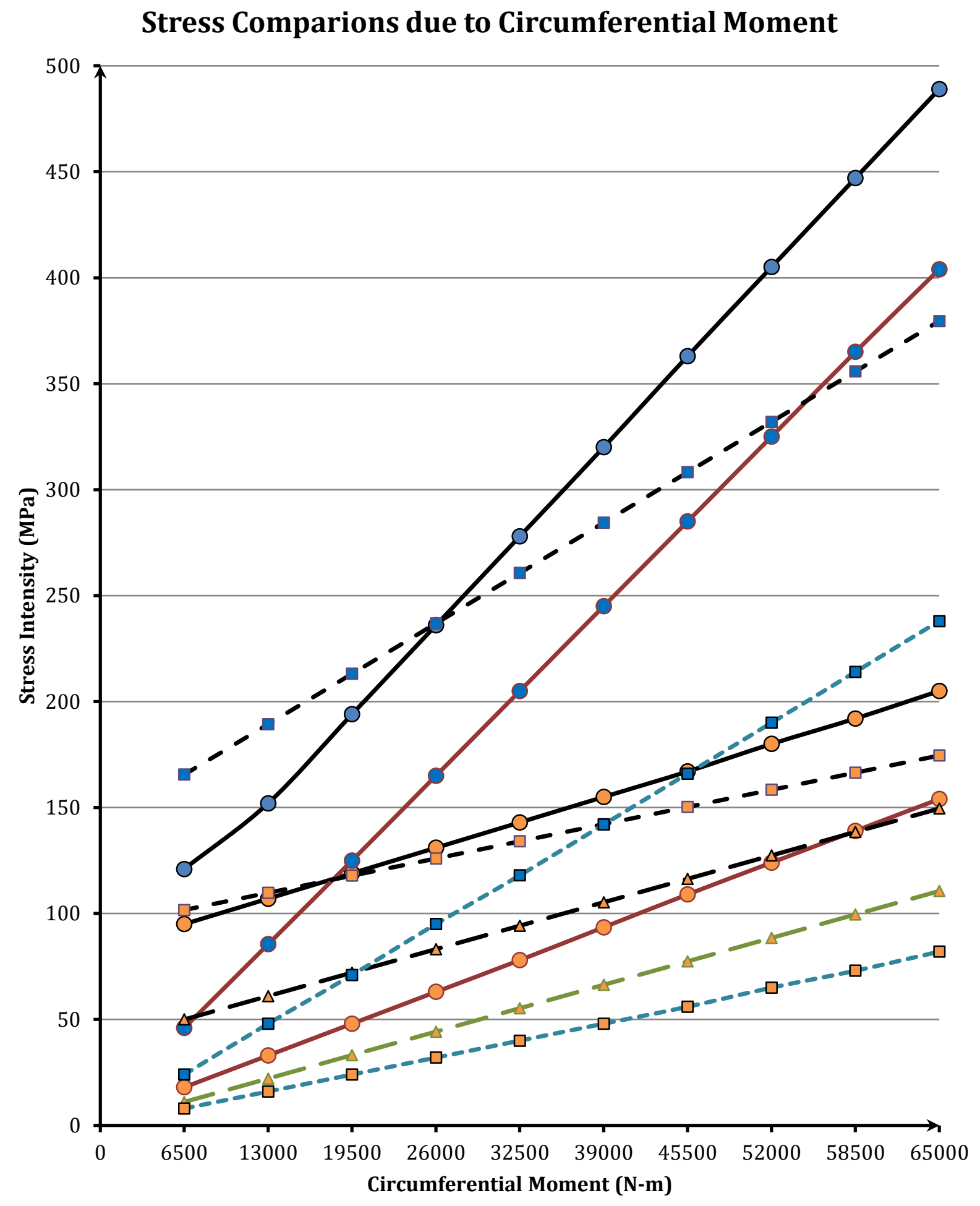

- - FEA with Pressure At Nozzle
- FEA without Pressure At Nozzle
- - WRC 107 with Pressure At Shell
$-\square-$ WRC 297 with Pressure At Nozzle

Figure 2 Circumferential Load Case 


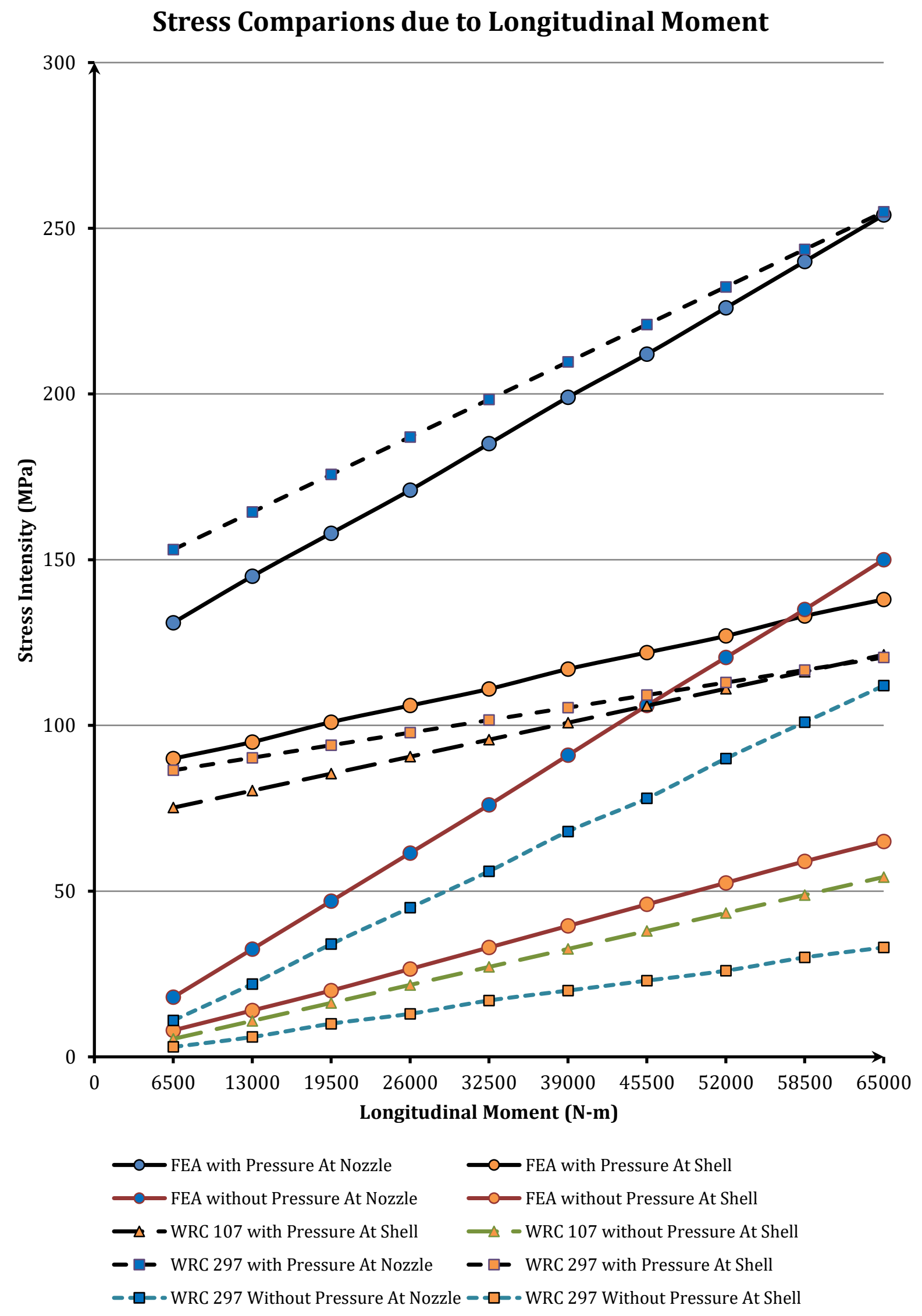

Figure 3 Longitudinal Moment Load Case 


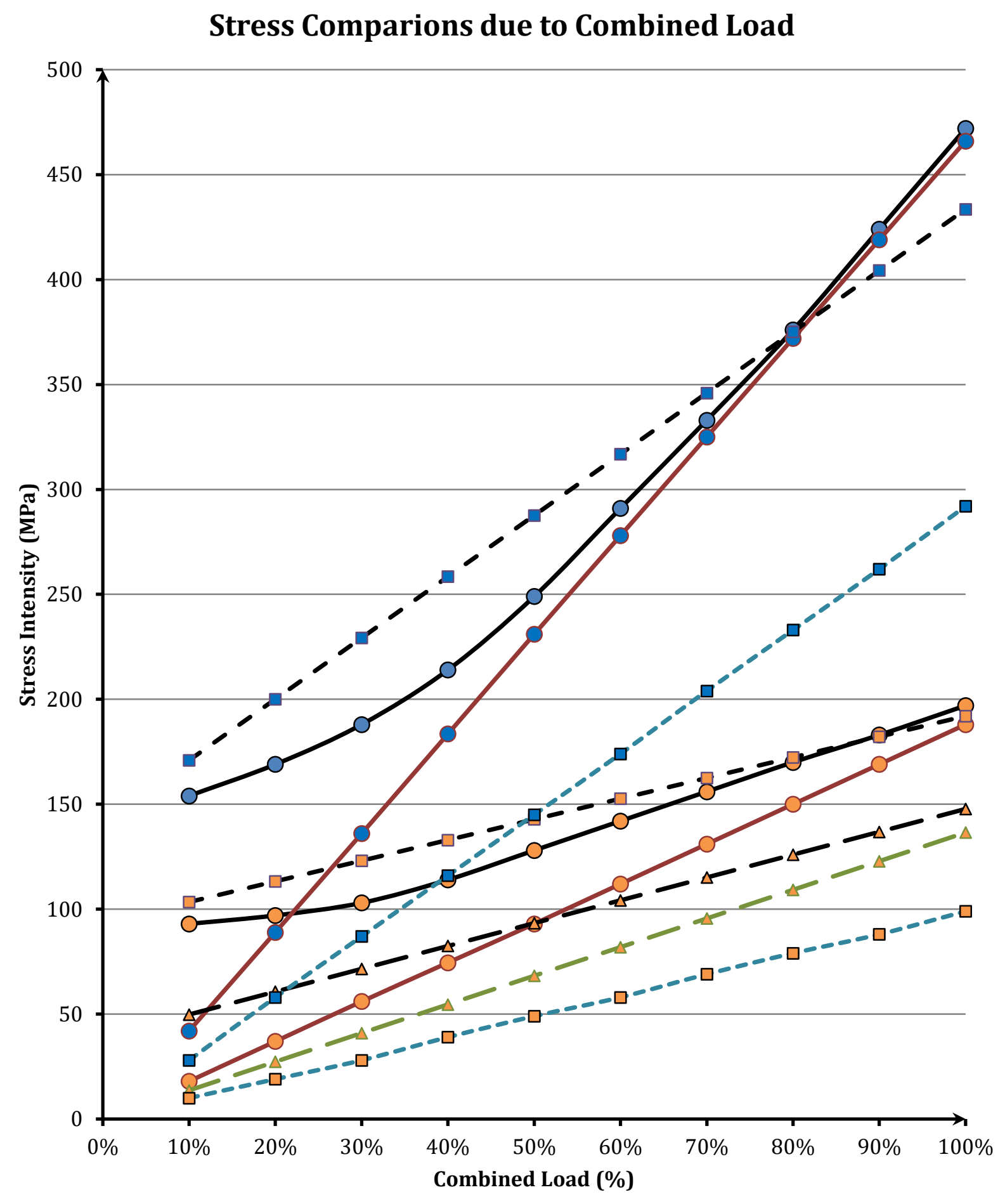

- FEA with Pressure At Nozzle

- FEA with Pressure At Shell

- FEA without Pressure At Nozzle

- - FEA without Pressure At Shell

$\longrightarrow$-WRC 107 with Pressure At Shell

$\triangle-$ WRC 107 without Pressure At Shell

- - WRC 297 with Pressure At Nozzle

- $\square$ - WRC 297 with Pressure At Shell

$-\square-\cdot$ WRC 297 Without Pressure At Nozzle - $-\bullet \cdot$ WRC 297 Without Pressure At Shell

Figure 4 Combined Load Case 


\section{VII.RESULTS DISCUSSION}

- $\quad$ For Axial load case major stress type found was bending stress. Membrane stress was only $28 \%$ of the bending stresses. The combined stress intensity was found close to bending stress. This is due the nature of the load due to which nozzle is pushed inside of the vessel and creating high bending stresses. In nozzle junction membrane stresses were found almost equal at junction and other areas of nozzles. It is to be noted here that in absence of pressure loading this stress will be compressive if axial load is directed inside of the vessel.

- For Longitudinal or In-plane moment case again the bending stress was very high. The membrane stress was only $35 \%$ of the bending stress. The bending stress was due the moment loading which created bending moment as the junction resulting in high bending stresses. The combined stress was highest at inner surface of the junction. This is because at inner surface the effect of bending and membrane stress is added which creates high stresses in inner surface.

- For Circumferential or Out-Plane moment case very high stresses were found. Combined stress was 2.5 times more than the stress found in In-Plane moment case. The high stresses in this case could be due to low stiffness of vessel in circumferential direction.

- Vessel under combined loadings the stresses calculated was comparative to the stress due to circumferential case. This is one reason for this result is that only axial loading contributed its role in both longitudinal and circumferential direction while longitudinal moment contributes very little role in circumferential direction and Out-Plane moment plays a little role for stresses in longitudinal direction. The location of maximum stress was found close the circumferential axis but was not at same location as it was for circumferential load case.

\section{CONCLUSIONS:}

- For load cases the maximum stress was in nozzle wall for pad reinforced nozzle. The stress in nozzle wall was found about 2-2.7 times more than stress in shell at junction.

- Circumferential moment has the highest impact on stress intensities. The stresses due to circumferential moment were 2.8 times more than the stresses due longitudinal moment.

- By graphical results it was found that maximum stresses will not be necessarily on one of the major axis. In combined loading the maximum stress was found in between the major axis. But it was more inclined to circumferential axis.

- Bending stresses were found playing more role in stress intensities values than membrane stresses.

- For axial load case and vessel under pressure, the maximum stresses obtained were from WRC 297 calculations while WRC 107 stresses were lower than FEA results. The large variation in stresses, from WRC 297 and FEA, at maximum loads were due to the canceling effect of tensile stress due pressure and compressive stress due axial in FEA calculations. While in WRC 297 it is common practice to calculate the pressure stress and then add it in analytical calculations separately. Otherwise both WRC 297 and FEA results can be considered conservative. For axial load case without pressure FEA results were found higher than WRC 297 stresses in nozzle wall while almost equal stress values were calculated in shell wall from all three methods.

- For circumferential moment large difference in stress values was found between WRC 297 and FEA results. FEA stress was found $20 \%$ more than WRC 297. While almost same stresses in shell at junction were found with both methods. Stresses from FEA were found higher than the other analytical methods.

- For longitudinal moment under pressure loading, almost same stresses in nozzle wall were found from both FEA and WRC 297. While in shell wall the difference between FEA and WRC analysis was $14 \%$. High stress values were found from FEA than other two methods for both with and without pressure.

- For combined loading under pressure, stresses in nozzle from FEA were found $11 \%$ higher than stresses obtained due to WRC 297. While very large difference in stresses in nozzle wall was found for vessel without pressure.

- For all load cases FEA results were found to give highest stresses in both shell and nozzle wall.

- WRC 297 was found more conservative than WRC 297 for vessel under internal pressure.

- WRC 107 results were found to give higher stresses than WRC 297 for vessel without pressure.

\section{RECOMMENDATIONS:}

On the basis of the above results and conclusions the author presents some recommendation while performing analysis of nozzle connections.

1. The nozzle thinner than the shell wall must be checked with extra care if the stresses in shell are high as per WRC 107 then alternate procedures like FEA or WRC 297 must be used to check the safety of nozzle.

2. For large pad reinforced nozzles with high circumferential loads the designer should check the stresses and assess if FEA analysis is required. If stresses are within $20 \%$ range of maximum allowable stress then FEA must be used for the nozzle analysis.

3. Author has presented a method of FEA for the analysis based on previous work and good engineering practices. But designer should ensure that the method will give reliable results for his/her geometry.

4. Boundary conditions must be double checked and iteration must be performed to check the validity of FEA.

The above procedure and recommendation assumes that the engineer will employ the recommended engineering practices, presented in other literatures, to ensure the validity of the FE model used for the analysis.

\section{ACKNOWLEDGMENT}

The author is thankful to Zamil Process Equipment Company for the resources provided for this work. 


\section{REFERENCES}

[1] Stresses at the Intersection of two Cylindrical Shells. M.D. Xue, W. Chen, K.C. Hwang. - : s.n., 1995, ELSEVIER Nuclear Engineering and Design, pp. 231-238.

[2] Nozzles-on External Loads and Internal Pressure. C. J. Dekker, H. J. Bos. - : ELSEVIER International Journal of Pressure Vessel and Piping, 1997.

[3] Limit and Burst Pressures with Cylinderical Intersection with Intermediate Diameter Ratio. Z. F. Sang, L. P. Xue, Y. J. Lin, G. E. O. Widera. - : ELSEVIER International Journal of Pressure Vessel and Piping, 2002.

[4] Plastic Limit Loads of Nozzles in Cylindrical Vessels under Out-ofPlane Bending Moment. Z. F. Sang, Z. L. Wang, L. P. Xue, G. E. O. Widera. - : ELSEVIER International Journal of Pressure Vessels and Piping, 2005.

[5] Limit Pressure and Design Criterion of Cylindrical Pressure Vessels with Nozzles. You-Hong Liu, Bing-Sheng Zhang, Ming-De Xue, You-Quan Liu. - : ELSEVIER International Journal of Pressure Vessels and Piping, 2004.

[6] Stress Analysis of Cylinderical Pressure Vessels with Load applied to free end of Nozzle. Aleksander Petrovic. -: ELSEVIER International Journal of Pressure Vessel and Piping, 2001.

[7] Design by Analysis versus Design by Formula of High Strength Steel Pressure Vessels: A Comparative Study. A.Th. Diamantoudis, Th. Kermanidis. - : ELSEVIER International Journal of Pressure Vessel and Piping, 2005.

[8] Comparative Study of Reinforced Nozzle Connections. V. N. Skopinsky. - : ELSEVIER Nuclear Engineering and Design, 1998.

[9] Pressure Stress Intensity at Nozzles on Cylindrical Vessels: A comparison of Calculation Methods. C. J. Dekker, W. J. Stikvoort. - : ELSEVIER International Journal of Pressure Vessel and Piping, 1997.

[10] James R. Farr Wadsworth. GUIDBOOK FOR THE DESIGN OF ASME SECTION VIII PERESSURE VESSELS. Second Edition. Ohio : s.n.

[11] -. ASME Boiler and Pressure Vessel Code-Division 2-Alternate Rules for Construction of Pressure Vessels. - : American Society of Mechanical Engineers, 2010.

[12] K. R. Wichman and A. G. Hopper. Local Stresses in Cylindrical and Spherical Shells due to External Loads-WRC 107. - : Welding Research Council, 1979.

[13] J. L. Mershon. Local Stresses on Cylindrical Shells due to Loadings on Nozzles-WRC 297. - : Welding Research Council, 1987.

[14] On Using Finite Element Analysis for Pressure Vessel Design. M. A. Porter, DH. Martens and P. Marcal. - : ASME Publications-PVP, 1999.

[15] A Proposed Method for Finding Stress and Allowable Pressure in Cylinders with Radial Nozzles. Bildy, Les M. - : ASME PUBLICATIONS-PVP, 2000.

[16] A Suggested Evaluation Procedure For Shell/Plate Element Finite Element Nozzle Models. Michael A. Porter, Dennis H. Martens. - : ASME Journal of Pressure Vessel Technology, 2008. 